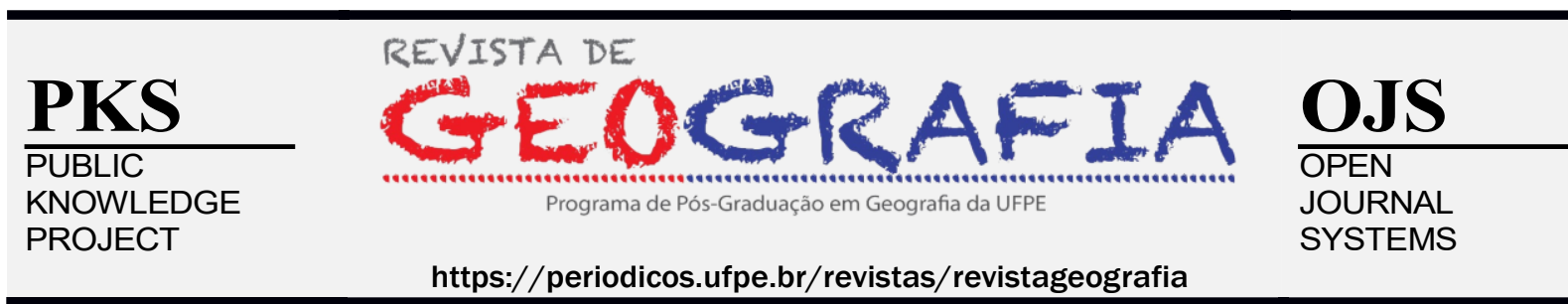

\title{
A GEOPOLÍTICA DOS ALIMENTOS, UMA PERSPECTIVA DA FOME À SOBERANIA ALIMENTAR: AS EXPERIÊNCIAS AGROECOLÓGICAS DAS CAMPONESAS NO CARIRI - CE
}

\author{
Bruna Dayane Xavier de Araújo ${ }^{1}$, Izabela Cristina Gomes da Silva ${ }^{2}$ \\ ${ }^{1}$ Doutoranda em Geografia (PPGG/UFC), Universidade Federal do Ceará, E-mail: bru.arauj@gmail.com, \\ Orcid: http://orcid.org/0000-0002-3397-2194 \\ 2 Doutora em Geografia (PPGG/UFC), Universidade Federal do Ceará, E-mail: \\ izabela.cristinagomes@gmail.com, Orcid: http://orcid.org/0000-0002-7605-2937
}

Artigo recebido em 03/11/2021 e aceito em 03/11/2021

\begin{abstract}
RESUMO
A questão da alimentação sempre foi um tema de suma importância, visto que é uma das necessidades fundamentais do ser humano e se apresenta como um direito inalienável. Além do fator biológico, o alimento é um conjunto de determinações simbólicas e afetivas que se remetem à apropriação do território, às relações sociais, culturais e de trabalho. Logo as configurações desses territórios estão atreladas ao direito humano à alimentação sadia e adequada de acordo com a idade, gênero, localização geográfica e à soberania alimentar. Então no presente artigo objetivamos investigar as experiências agroecológicas das mulheres camponesas na região do Cariri - CE e sua relevância para a soberania alimentar em um contexto regional. Assim como também analisar as estratégias de organização, gerenciamento dos agroecossistemas e implementação de feiras agroecológicas. Utilizamos uma metodologia qualitativa baseada em levantamento bibliográfico, pesquisa documental, trabalho de campo, entrevistas semiestruturadas, registros fotográficos e audiovisual. Ademais discutimos o papel das mulheres para o fortalecimento da soberania alimentar em níveis locais e em redes. Por fim verificamos que na região do cariri cearense as experiências agroecológicas realizadas camponesas vêm se mostrando uma alternativa para a produção de alimentos com qualidade, segurança e mais acessibilidade à população.
\end{abstract}

Palavras-chave: alimentação; mulheres camponesas; agroecologia; soberania alimentar; Cariri - CE.

\section{FOOD GEOPOLITICS, A PERSPECTIVE FROM HUNGER TO FOOD SOVEREIGNTY: THE AGROECOLOGICAL EXPERIENCES OF PEASANT WOMEN IN CARIRI, CE}

\begin{abstract}
The issue of feeding has always been an extremely important question, as it is one of the fundamental needs of human beings and presents itself as an inalienable right. In addition to the biological factor, food is a set of symbolic and affective determinations that refer to the appropriation of the territory, to social, cultural and work relations. Therefore, the configurations of these territories are linked to the human right to healthy and adequate food according to age, gender, geographic location and food
\end{abstract}


sovereignty. So, in this scientific article we aim to investigate the agroecological experiences of peasant women in the Cariri - CE and its relevance for food sovereignty in a regional context. As well as analyzing the organization strategies, management of agroecosystems and implementation of agroecological fairs. We used a qualitative methodology based on bibliographic survey, document research, fieldwork, semi-structured interviews, photographic and audiovisual records. Furthermore, we discussed the role of women in strengthening food sovereignty at local levels and in networks. Finally, we found that in the cariri cearense, the agroecological experiences carried out by peasants have been shown to be an alternative for the production of food with quality, safety and greater accessibility to the population.

Keywords: feeding; peasant women; agroecology; food sovereignty; Cariri - CE.

\title{
GEOPOLÍTICA ALIMENTARIA, UNA PERSPECTIVA DEL HAMBRE A LA SOBERANÍA ALIMENTARIA: LAS EXPERIENCIAS AGROECOLÓGICAS DE LAS CAMPESINAS DE CARIRI, CE
}

\begin{abstract}
RESUMEN
El tema de la alimentación siempre ha sido una cuestión de gran importancia, ya que es una de las necesidades fundamentales del ser humano y se presenta como un derecho inalienable. Además del factor biológico, la alimentación es un conjunto de determinaciones simbólicas y afectivas que hacen referencia a la apropiación del territorio, las relaciones sociales, culturales y laborales. Por lo tanto, las configuraciones de estos territorios están vinculadas al derecho humano a una alimentación sana y adecuada según edad, género, ubicación geográfica y soberanía alimentaria. Así pues, en este ensayo tenemos la intención de investigar las experiencias agroecológicas de las mujeres campesinas en la región de Cariri - CE y su relevancia para la soberanía alimentaria en un contexto regional. Como también analizar las estrategias de organización, gestión del agroecosistemas e implementación de ferias agroecológicas. Utilizamos una metodología cualitativa basada en levantamiento bibliográfico, investigación documental, trabajo de campo, entrevistas semiestructuradas, registros fotográficos y audiovisuales. Además, discutimos el papel de la mujer en el fortalecimiento de la soberanía alimentaria a nivel local y en redes. Por fin, verificamos que en la región cariri cearense las experiencias agroecológicas llevadas a cabo por las campesinas han venido exponer una alternativa para la producción de alimentos con calidad, inocuidad y más accesibilidad a la población.
\end{abstract}

Palabras-clave: alimentación; mujeres campesinas; agroecología; soberanía alimentaria; Cariri - CE.

\section{INTRODUÇÃO}

A questão da alimentação é um tema de suma importância, visto que é uma das necessidades fundamentais do ser humano e se apresenta como um direito inalienável. Além do fator biológico, o alimento é um conjunto de determinações simbólicas e afetivas que se remetem à apropriação do território, às relações sociais, culturais e de trabalho.

Então o presente artigo propõe trazer contribuições para a discussão sobre os seguintes temas: soberania alimentar, território e práticas agroecológicas. Assim, nos possibilitando uma compreensão mais aprofundada sobre a totalidade, que constrói a questão da alimentação. Nesse âmbito trazemos as experiências das mulheres camponesas na região do cariri cearense, suas estratégias de organização, gerenciamento dos agroecossistemas e implementação de feiras 
agroecológicas. Estas mulheres têm em suas histórias de vidas a luta pelo direito à terra e por acesso a crédito/programas sociais, como também vêm disputando espaços no campo políticosindical.

O cariri cearense, lócus da pesquisa, possui diversos conflitos resultantes de projetos de desenvolvimento e cosmovisões distintas para o território, mostrando-nos que a relação luta de classe - território é indissociável. Este estudo faz parte de reflexões iniciais de uma pesquisa de doutorado que se encontra em andamento. Utilizamos uma metodologia qualitativa baseada em levantamento bibliográfico, pesquisa documental, trabalho de campo, entrevistas semiestruturadas, registros fotográficos e audiovisual, objetivando assim captar narrativas de vida e participar de atividades cotidianas das camponesas investigadas.

A pergunta motivadora é entender como as experiências agroecológicas que vêm sendo realizadas pelas camponesas, em paralelo ao mercado e modelo agrícola hegemônico, se revelam enquanto uma alternativa para produção de alimentos com qualidade, segurança e mais acessibilidade à população? À vista disso buscamos investigar essas experiências das camponesas (produção, distribuição e comercialização) na região do Cariri - CE e suas relevâncias para um diálogo e edificação de um projeto de soberania alimentar em um contexto regional. Bem como trazer uma discussão teórica sobre o tema.

Nesse âmbito a soberania alimentar revela-se enquanto horizonte construído no berço da materialidade dos movimentos sociais e possui como pedra angular a agroecologia. Referese ao direito dos povos a alimentos nutritivos, culturalmente adequados, acessíveis, produzidos de forma ecológica, e ao poder de decidir seu próprio sistema alimentar-produtivo (VIA CAMPESINA, 2004). Ou seja, os povos camponeses escolhem o que plantar e produzir pensando em atender prioritariamente a demanda interna. Assim as mulheres vêm se apresentando como sujeitos importantes nas práticas agroecológicas, sendo pilares importantes para a materialização da soberania alimentar. Então, vamos nos enveredar nesses trajetos, que constroem a comida saudável e socialmente justa.

\section{ALIMENTOS, O TABU DA FOME E GEOPOLÍTICA DOS ALIMENTOS}

O alimento é uma fonte vital para os seres humanos. É o que nos mantém vivos e nos dá condição para realizar as demais outras atividades, projetos e planos em nossa existência individual e social. A alimentação é um dos motivos mais cruciais que move cotidianamente a 
classe trabalhadora a sair para exercer suas atividades laborais, mesmo em uma realidade tão desigual, contraditória e de exploração.

No intuito de não cairmos em uma concepção reducionista da alimentação, entendendoa apenas como uma necessidade biológica, a abordagem principal desta pesquisa será no sentido de compreender as relações complexas e socioculturais, que atravessam a produção de alimentos.

Nesse contexto a alimentação se apresenta, primeiramente, como uma necessidade biológica, somado a isso é um complexo sistema simbólico que aglomera diversos significados: sociais, de prazer, sexuais, políticos, religiosos, éticos e estéticos. (CARNEIRO, 2003). Logo a alimentação é um eixo central para entender as redes sociais e é um dos pilares primordiais na construção da nossa sociedade.

Marx (2010) explica que o alimento se refere à relação com o trabalho, à construção de um ser humano genérico, ao vínculo com a natureza e com a sua própria natureza. Sendo anterior ao processo de alienação, o alimento e a sua apreciação constroem processos mais complexos de sociabilidade e cultura. Assim alimentar-se é uma prática genuinamente humana, no sentido que desenvolve a própria humanidade/sociedade. Por conseguinte, quando a alimentação é permeada pelo processo de alienação, torna-se um processo com uma única finalidade, ou seja, o trabalho busca garantir tal necessidade fisiológica. Construindo um regime não criativo, onde as pessoas se afastam da consciência de sua própria existência. Dessa forma, o ato de alimentar possui uma função empobrecida de significados, apenas vinculado a uma visão reducionista como algo meramente biológico.

A cadeia agroalimentar, ou o percurso do alimento, se refere a muito mais que o trajeto do prato à boca e as compras em um supermercado. $\mathrm{O}$ acesso e a gestão de determinados alimentos possuem um campo invisível de processos históricos e construções culturais. Contendo também as relações de poder e a materialização das relações sociais/laborais, assim construindo a geopolítica dos alimentos.

Atualmente, os regimes alimentares se referem às formas como a cadeia alimentar se interligam através da mercantilização, transformando os espaços e as relações sociais. E são elementos importantes no papel de acumulação de capital. McMichael (2016) descreve três importantes fases dos regimes alimentares: 1) Imperial, determinado pela Grã Bretanha (1870 -19302), 2) Centrado nos Estados Unidos (1950 -1970); 3) Corporativo, dirigindo pelas grandes corporações (1980 - 2000). 
Porém para entendermos mais profundamente a concretude do que estamos analisando, no caso a alimentação, seus processos de produção, distribuição e acesso, precisamos dar um passo atrás e refletirmos sobre a fome. Este estado que causa incômodo, provoca suplícios, dores prolongadas e um mal-estar profundo.

Mas o que é fome, afinal? É a situação em que indivíduos em seu cotidiano não tem acesso à comida, sofrendo a violência de não ter o que se alimentar. Josué de Castro chama atenção também para fome parcial ou oculta, na qual pela falta permanente de nutrientes em seus regimes alimentares, grupos inteiros de população morrem lentamente de fome, apesar de comerem todos os dias. (CASTRO, 2006).

O autor ainda diferencia mais dois tipos de fome: a endêmica e epidêmica. Esta última restrita a períodos de escassez de chuvas. A endêmica está vinculada à estrutura agrária do latifúndio e ao seu caráter de monocultura de exportação. Castro (2006) cita como exemplo a zona da mata, no nordeste brasileiro, com solos férteis e chuvas abundantes, mas onde a fome estava bem presente. Nesse sentido, é preciso compreender os processos políticos que envolvem o problema da fome. "Enquanto a sua repercussão é global ou nacional, a fome é regional ou local, evidenciando as desigualdades regionais com seus processos econômicos, sociais e políticos geradores da fome regionalizada." (SAMPAIO, 1999, p.22).

Castro (1965) utiliza o termo "monotonia alimentar" que significa o hábito do homem de nutrir-se à base de um número restrito de substâncias alimentares, devido à diminuição ao acesso à diversidade de alimentos. Eduardo Galeano, em As veias abertas da América Latina, explica que a história do subdesenvolvimento da América Latina integra a história do desenvolvimento do capitalismo mundial. Nossa riqueza gerou nossa pobreza para nutrir a prosperidade alheia.

Exportamos produtos, e também os nossos solos e subsolos. Terras que poderiam atender as necessidades essenciais do mercado interno são destinadas a um só produto, à serviço da demanda estrangeira. A monocultura é uma prisão. A diversidade, ao contrário, liberta. (GALEANO, 2018, p. 07)

Nessa conjuntura a fome é um processo de relações sociais historicamente construídas em um determinado espaço. Assim apontamos a distribuição como um elemento importante para se pensar o acesso à alimentação, divergindo do contexto de excessiva concentração dos alimentos. Porto-Gonçalves também coloca que "o modelo de distribuição não é separado do modo de produção, todo modo de produção é, ao mesmo tempo, um modo da distribuição." (PORTO-GONÇALVES, 2006, p. 288). 
No Brasil, historicamente existe um tabu para enfrentar esse problema social. Somente em 1990 foi produzido um mapeamento sobre as condições sociais do país, com um mapa da fome. À vista disso em 1993 foi criada a Política Nacional de Segurança Alimentar e Nutricional (PNSAN) e o Conselho Nacional de Segurança Alimentar (CONSEA). Já nos anos 2000 surgiu o programa Fome Zero.

Então a origem da fome é estrutural e está nas raízes da formação social de cada país, de cada estado-nação. Logo a fome no Brasil é consequência de seu passado histórico-social, e encontramos o seu cerne desde os períodos da colônia. "As causas da fome estão mais vinculadas aos fatores socioculturais e econômicos que aos de natureza geográfica." (CASTRO, 2006). Para o autor, "a fome é a mais trágica expressão do subdesenvolvimento".

Na obra Regime alimentares e questão agrária, de Philip McMichael, são apresentadas as relações históricas entre construção do Estado, colonização de terras, rotas alimentares e padrões alimentares. Nessa abordagem os regimes alimentares são construídos no âmago das relações de produção, consumo e trabalho, como também a partir dos ajustes estruturais no modo de produção capitalista.

Portanto na lógica capitalista os alimentos se tornam mercadorias, perdem sua essencialidade e passam a serem encarados como fonte de extração para geração de lucros. No Brasil, a produção de commodities aumentou consideravelmente, sobretudo na década dos anos 2000, construída desde a lógica da exportação, produção em larga escala e monocultura. Consequentemente os incentivos fiscais vindos do Estado brasileiro são, majoritariamente, para desenvolver o agronegócio. Assim marginalizando a produção de alimentos para a demanda interna, historicamente produzida pela agricultura familiar camponesa.

O agronegócio brasileiro é um modelo de produção caracterizado pela mecanização da produção, uso de tecnologias no plantio, irrigação e colheita. Por isso a produção agrícola brasileira está inserida na reestruturação produtiva, que determina um papel específico aos países do sul na divisão internacional do trabalho, direcionando suas economias para produção de commodities (RIGOTTO, 2015).

Assim é importante frisar que grande parte da produção do agronegócio é destinada às demandas do mercado externo. Logo o papel do Brasil na divisão internacional do trabalho traz caras consequências à população do nosso país. Pois esse setor econômico utiliza até a exaustão das forças de trabalho, como também até gerar infertilidade nos solos e perca da biodiversidade. Além de desencadear processos de degradação ambiental, desmatamento, grilagem, 
concentração de terras/riquezas e conflitos no campo. Por conseguinte, a alta utilização de agrotóxicos para aumentar a produtividade e os lucros, tem deixado para os trabalhadores a contaminação do meio ambiente, dos alimentos, e problemas de saúde pública a níveis imensuráveis.

Nesse contexto, observa-se um processo intenso de fusões e aquisições entre os grandes grupos transnacionais (produtores de sementes, agroquímicos e alimentos, empresas biotecnológicas, grandes cadeias internacionais de supermercados, etc.). A partir desses ‘conglomerados alimentares' chegam ao consumidor/trabalhador alimentos baratos e empobrecidos nutricionalmente, frutos da acumulação do capital em escala global. (MCMICHAEL, 2016).

Porto-Gonçalves (2006) explana a necessidade de o mundo conhecer o custo socioambiental, que está por trás da produção de commodities. Estas são comercializadas no mercado global às custas do trabalho de agricultores e agricultoras em condições precarizadas com jornadas 'intermináveis', baixos salários e vulneráveis em relação aos direitos (trabalhistas, das mulheres, humanos).

Além disso causando fome e subnutrição, por mais contraditório que possa parecer. No centro desse debate sobre a fome, ausência de alimentos/nutrientes adequados e crise alimentar, surgem enquanto pauta das populações do campo alternativas a partir do paradigma agroecológico, que se desdobraram na luta por soberania alimentar.

\section{OS ELOS ENTRE A AGROECOLOGIA, TERRITÓRIO E SOBERANIA ALIMENTAR}

A soberania alimentar é o direito de cada povo de definir suas próprias políticas agropecuárias e, em matéria de alimentação, de proteger e regulamentar a produção agropecuária nacional/mercado interno, a fim de alcançar metas de desenvolvimento humano sustentável. (Machin Sosa, 2012). Isso coloca aqueles que produzem, distribuem e consomem alimentos no coração dos sistemas e políticas alimentares, acima das exigências dos mercados e das empresas. (Via Campesina, 2004).

Desse modo a soberania alimentar é oposta ao modelo agroexportador do agronegócio. Esta não surge do nada ou de abstrações, é resultado de processos históricos e sociais das organizações dos movimentos sociais do campo. (JALIL, 2009). A partir deste conceito há uma disputa de poder nos sistemas agroalimentares em diferentes escalas (local, regional, nacional, global) sob a lógica do campesinato. Visa também responder a "perda de capacidade dos 
estados nacionais para formularam políticas agrícolas e alimentares no contexto da progressiva internacionalização da economia”. (MENEZES, 2001, apud, MALUF, 2007, p. 22).

Logo a soberania alimentar propõe desenvolver estratégias de romper com as condições históricas dos países dependentes/subdesenvolvidos, Brasil, por exemplo, como agroexportador de commodities. Construindo condições para produção de alimentos ricos em diversidade e qualidade. Tornando a alimentação mais acessível à população, ao mesmo tempo, que se preocupa com as estruturas sociais no campo e na cidade. Buscando propiciar a permanência dos camponeses no espaço agrário, a qualidade de vida e de trabalho, concomitantemente, garantir aos povos o direito à alimentação adequada e permanente.

A luta pela soberania alimentar se contrapõe à lógica do neoliberalismo, repolitizando as esferas pública e estatal. Relaciona-se a um conjunto de políticas públicas que devem ser articuladas e implementadas, trazendo a dimensão do local como espaço privilegiado e fundamental para a concretização destas políticas em conjunto com o protagonismo e a participação das pessoas, que são efetivamente os sujeitos políticos dos processos de transformação, como uma ação construída — de baixo para cima baixo. (JALIL, 2009, p. 60)

A pedra angular da soberania alimentar é a agroecologia. Nesse sentido, também é necessário refletir sobre o conceito agroecológico. Este possui várias dimensões: política, agronômica, ecológica, econômica e social. Os sujeitos protagonistas pela a transição agroecológica são os camponeses. Assim, a agroecologia discute também a territorialização do espaço agrário sob uma ótica camponesa.

Os principais princípios da agroecologia são a integralidade, minimização de externalidades negativas das atividades produtivas, os circuitos curtos de produção, manejo ecológico da natureza, pluriatividade. (COSTA, 2017). Ademais a agroecologia propõe a produção de alimentos também em áreas urbanas e periurbanas. Pois as cidades precisam ter ambientes cultiváveis, diversificar os equipamentos públicos de alimentação/nutrição e estimular as feiras agroecológicas.

A agroecologia deve ser entendida não apenas como substituição de insumos químicos por biológicos. Schmitt (2009) explica que essa forma de fazer agricultura não depende apenas da preservação dos recursos naturais utilizados nos processos produtivo, mas do fortalecimento de novas redes de relações que desempenham um papel importante na sustentabilidade social e econômica desse novo modo de vida.

Na defesa pela agroecologia e soberania alimentar, a Via Campesina é uma peça chave. Esta é um agrupamento a nível global de organizações e movimentos sociais camponeses, agricultores familiares, povos indígenas, camponeses sem terra. 
Para disputar o projeto territorial do capital no campo, a VC quer levar a agroecologia camponesa e popular à escala territorial, como parte do seu projeto de Reforma Agrária Popular. conseguir sua massificação ou territorialização significa que, ao invés de ser praticada por poucas famílias em um território pequeno, torna-se uma prática de muitas famílias em um território grande. (BARBOSA; ROSSET, 2019, p. 47).

O projeto de soberania alimentar se mostra intimamente ligado a um programa político que, tem como base os interesses das classes populares e aponta para o rompimento das relações de exploração e desigualdades sociais, se caracterizando como um projeto de mudança da estrutura social em âmbito regional, nacional e global. A Via Campesina defende o conceito de soberania alimentar "superior ao da segurança alimentar", aquele conceito vai além do "direito aos alimentos" e defende o papel dos povos do campo na produção de alimentos, implicando nas obrigações do Estado de proteger os mercados locais e de implementar a reforma agrária. (ROSSET, 2018).

À vista disso aponta a gestão da terra-território como instrumento que possa garantir o direito à alimentação com alimentos saudáveis para classe trabalhadora. Assim, está vinculada também à defesa dos direitos camponeses.

Nesse âmbito a alimentação é a luta contra a fome, já a soberania alimentar, produto de práxis, surge como alternativa às condições de fome decorrente de insuficiência no âmbito do abastecimento. (PAULINO, 2012). Logo a soberania alimentar visa recuperar a função social da terra para prover a vida produzindo alimentos. Nesse sentido, o debate sobre reforma agrária é uma das bandeiras de luta.

No espaço agrário há dois principais eixos da agroecologia são: os quintais produtivos e as feiras agroecológicas. Os quintais produtivos são uma fonte de diversificação de culturas alimentares, mas também são espaços de encontro e socialização, produção de saberes. Enquanto as feiras agroecológicas são espaços de sociabilidade para conhecer os produtores, comprar a preços mais acessíveis e saber a origem dos alimentos, onde temos a garantia que não estamos comendo "alimentos vazios". Por fim é um espaço de formação de consciência alimentar, troca de saberes, de consumo justo. Os consumidores das feiras agroecológicas, ao longo do tempo, se assumem como defensores desses canais de escoamento da produção e percebem que os alimentos e os seus sabores, cheiro e estética são diferentes dos alimentos vindos do agronegócio.

Então a agroecologia vem se inserindo nesse contexto, se torna um instrumento de defesa dos territórios camponeses e seus paradigmas de produção. E através deste movimento há o processo de re-territorialização. Dutra Jr; Dutra (2008, p. 206) nos trazem que “[...] o 
território camponês se materializa na unidade da produção familiar, lá está a possibilidade da garantia da (re)produção camponesa, que lhes permite permanecer e se fixar na terra”.

Os camponeses dominam as culturas alimentares que proporcionam menores rendimentos. É levado em consideração a capacidade de consumo interno da produção, na iminência de percalços no momento da comercialização. Isso é uma das explicações de privilegiamento da produção de alimentos básicos. (PAULINO, 2012, p.53).

Marques (2008), a partir de uma leitura de Shanin (1983) explica que as especificidades camponesas são o cultivo da terra, unidade de produção familiar e/ou comunitária e posição como classe mais baixa da sociedade. A propriedade camponesa é constituição interna de trabalho e também de sociabilidade, onde é priorizado primeiramente o autoconsumo e posteriormente abastecimento externo. Bartra (2011) explana sobre as transformações do camponês enquanto símbolo de resistência e de relações de solidariedade. Possui um suporte material (terra) e a sua força de trabalho, a terra como meio de produção e espaço de autogestão.

Nessa perspectiva o conceito de camponês, para além da atividade econômica, como produtor de alimentos, possui outras características, como o legado cultural passado de geração a geração ao longo do tempo. Existem especificidades que devem ser levadas em consideração ao tratar com os camponeses, desde a sua relação com o ambiente no qual estão inseridos até as relações sociais e culturais que influenciam os seus modos de vida.

Então ressaltamos que soberania alimentar perpassa as dimensões da produção, distribuição e circulação de alimentos. Torna-se eixo fundamental para se pensar outra realidade agrária e outros modos de produzir alimentos no país. Desse modo, compreendemos que está em questão o consumo e a distribuição dos gêneros alimentícios, mas também a produção agrícola e a estrutura social brasileira. Sobretudo as origens agrárias do Brasil e do Cariri-CE, que têm como base a lógica capitalista e a sua inserção no mercado internacional, não atendendo às demandas da população local.

Logo a produção de agrícola seja a partir de commodities (grãos, fibras, combustíveis) para o mercado internacional ou alimentos derivados da agricultura familiar para abastecimento interno revelam a multiplicidade de usos dos territórios agrários. Por exemplo, nos espaços territorializados pelo Agronegócio os usos desses territórios vêm anulando os sujeitos sociais e as relações sociais não incorporadas à lógica capitalista. Por isso falamos em território camponês e território do agronegócio, maneiras diferentes de territorializar um dado espaço. Assim o alimento é um fragmento do território.

Hablamos de la soberanía alimentaria como territorio porque el término contiene uno de los principios fundantes del concepto: la soberanía. Recuperar el poder de producir 
alimentos para el consumo local es un factor diferencial que caracteriza el territorio de la soberanía alimentaria. (FERNANDES, 2017 p. 35)

Desse modo, a soberania alimentar é o território do camponês. Pensar na produção dos alimentos a partir da biodiversidade é proteger o território onde eles são produzidos. Defender a ideia de soberania alimentar é transformá-la em políticas públicas, e posicionar-se contra as políticas de commodities da agricultura exportadora (o agronegócio), que mantém a fome no mundo. Significa priorizar a qualidade dos alimentos para resguardar a saúde pública, usar as tecnologias para a conservação do meio ambiente. (FERNANDES, 2017).

Esse autor também traz um questionamento: Por que a ideia de soberania alimentar não nasceu do agronegócio? Para ele a soberania alimentar exige a divisão dos poderes para a tomada de decisão sobre o que produzir e onde fazê-lo. E não ficar apenas à mercê dos 'temperamentos' do mercado interno.

À vista disso o território está ligado à noção de limite, pois mesmo não sendo traçado, exprime relações de poder que um grupo mantém com uma porção do espaço. O poder não é objeto, ou coisa, mas uma ideologia e uma relação vinculada as suas redes e mobilidades estabelecidas. As multidimensionalidades do território estão no sentido de apreendê-lo na vertente funcional (dominação) e simbólico (apropriação). Dominação: concreto, político, econômico. Apropriação: simbólico, afetividade e identidade. Por fim um território imerso em relações de dominação e/ou de apropriação sociedade-espaço, "desdobra-se ao longo de um continuum que vai da dominação político-econômica mais 'concreta' e 'funcional' à apropriação mais subjetiva e/ou cultural-simbólica.” (HAESBAERT, 2004, p. 95-96).

Ademais as representações das formas de uso do território trazem o debate sobre territorialidades. As produções materiais se constroem dialogando com as produções imateriais, os aspectos políticos com os culturais. A territorialidade está intimamente ligada ao modo como as pessoas utilizam o território, como elas próprias se organizam no espaço e como elas dão significado ao lugar (Haesbaert, 2004). É interessante refletir que o alimento é um "fragmento" do território e das relações sociais contidas nele.

\section{AS EXPERIÊNCIAS AGROECOLÓGICAS DAS MULHERES CAMPONESAS DO CARIRI CEARENSE}

Os regimes agroalimentares hegemônicos buscam fortalecer o agronegócio. Nesse sentido, a agricultura camponesa é invisibilizada. Há uma marginalização dos camponeses que possuem um papel relevante e primordial de alimentar a classe trabalhadora pelo mundo. 
Dentro da agricultura familiar e camponesa, o papel das mulheres ainda é majoritariamente invisibilizado, apesar de bastante ter relevância e ser um pilar importante na engrenagem da produção de alimentos. Assim, como existe um conflito de classes, de disputa por território e por modelo de produção de alimentos, existem também desigualdades de gêneros, no qual o papel das mulheres se torna repleto de elementos de opressão e exploração na relação assimétrica entre camponeses/agricultores e os latifundiários, mas também dentro da própria classe trabalhadora camponesa.

O corpo da mulher no agronegócio é atingido duplamente pela exploração do trabalho, quando está trabalhando para as agroindústrias e também em seus lares. Por exemplo, as mulheres camponesas entram em contato novamente com os agrotóxicos ao lavarem as roupas de seus maridos. A mesma lógica explora as mulheres, as terras e a natureza, produzindo alimentos com vários custos ambientais, fortalecendo a divisão sexual do trabalho e da reprodução social. Quando estamos discutindo sobre as mulheres é inevitável falarmos sobre esta, que é um conjunto de tarefas designadas socialmente às mulheres, como se fossem algo inerente a sua natureza.

É o trabalho de produção de pessoas que supre algumas das pré-condições - materiais, sociais e culturais, fundamentais para a sociedade humana em geral e para produção capitalista em particular. Sem ele, nem a vida nem a força de trabalho estariam encarnadas nos seres humanos. Chamamos esse amplo corpo de atividade vital de reprodução social. (ARRUZA, BHATTACHARYA E FRASER, 2019, p. 111)

Entre os exemplos concretos que podemos citar: o papel do cuidado da casa, da família e da comunidade. Isso colocando restrições aos espaços que elas devem circular, sendo-lhes o espaço privado mais familiares do que os espaços públicos, de decisões e das atividades econômicas principais. No caso da agricultura, as atividades consideradas mais rentáveis são muitas vezes lideradas pelos homens da casa, as mulheres ficam responsáveis pelas atividades domésticas, a "ajudarem" os maridos nas roças e cuidarem dos quintais produtivos, consideradas atividades acessórias. O trabalho assalariado não poderia existir, sem o trabalho não pago.

En el caso de las mujeres rurales, cuando hablamos de trabajo invisible, nos referimos a ese trabajo doméstico no remunerado, pero también a lo que podría ser considerado como trabajo productivo estricto, que sin embargo no se registra en las cuentas nacionales porque se considera como una extensión de las tareas de reproducción biológica y de la reproducción de la fuerza de trabajo. El cuidado de las huertas, de los animales, de las semillas, la recolección de frutos, la búsqueda del agua, se vuelven parte de las tareas no remuneradas y consideradas como no productivas, aunque provean de alimento, y hagan a las condiciones de sobrevivencia de millones de personas en el mundo. (KOROL, 2016. P. 92) 
No território rural, o peso do machismo e do patriarcado é bastante forte. O desenvolvimento de políticas que fortaleçam a agroecologia e soberania alimentar é urgente, na medida em que auxiliam no combate a essas estruturas de opressão. Geralmente, o trabalho agrícola das mulheres é considerado um trabalho doméstico, logo estão inseridas nas tarefas de reprodução social. "Es decir, una extensión de sus atribuciones como madre, esposa y ama de casa" (KOROL, 2016, p. 102). A invisibilidade das mulheres (dos seus trabalhos) está naturalizada na divisão sexual do trabalho. Sustentando a ideia de que existe trabalho para homens e trabalhos para as mulheres.

É importante salientar o papel das mulheres na história da agricultura, desde os primórdios até os tempos atuais, em que elas se apresentam como importantes protagonistas na defesa dos seus territórios, compreendendo-os como local de produção e de sociabilidade. Além de suas ligações com a preservação da cultura alimentar regional e também com os procedimentos de enfrentamento à subnutrição, sobretudo dentro da família. Construindo então estratégias para beneficiar a saúde humana. (SILIPRANDI, 2015). Se a alimentação é resultante de fatores socioeconômicos e das relações sociedade-natureza, as mulheres cumprem um papel de eixo central nessa temática,

Desse modo, a pesquisa vinculada a tese de doutorado, vem se enveredando nas reflexões da trajetória de oito mulheres camponesas da região do Cariri, ao sul do estado do Ceará, Nordeste do Brasil. A região do Cariri está localizada em na Chapada do Araripe, possui vegetação e águas perenes, possuindo uma gama de biodiversidade, contrastando com o sertão semiárido que o cerca. Contudo, a região vem passando por sérios problemas hídricos e socioambientais devido ao desmatamento e queimadas, trazendo como consequência o lixiviamento do solo.

Menezes (2007) coloca que a região do Cariri é uma área úmida de brejo, teve seu processo histórico tendo como base a agroindústria canavieira e em menor porte o algodão, a agricultura para o autoconsumo e pequena comercialização para o mercado local. Na década de 1940 os engenhos chegam a 300, produzindo rapadura e aguardente para todo interior do Nordeste, especialmente, para atender as demandas vindas de Pernambuco. O processo histórico do Cariri esteve interligado em atender as demandas da produção de cana- de açúcar.

Os canaviais que marcaram o cenário desta região eram controlados por poucas famílias concentradoras de terra, desenvolvendo-se relações marcadas por violência, conflitos e explorações. Ao mesmo tempo, esse contexto impulsionou processos de organização das 
classes subalternas vinculados às associações, uma parte da Igreja Católica - Pastorais da terra e a sindicatos.

A partir da conjuntura da questão fundiária no Cariri, Silva (2010) expõe que essa problemática se apresenta de forma bem paradoxal, pois encontramos uma presença numérica significativa de minifúndios e também uma grande concentração fundiária, decorrente do acúmulo de grandes extensões de terras na posse de poucos proprietários. Logo muitos minifúndios ocupam poucas porcentagens de terras, e poucos latifúndios ficam com a porcentagem maior de terras. Silva (2010) explica que esse panorama tem sua origem no processo de ocupação do cariri cearense, desde os primeiros casos de violências contra os povos originários, os índios Kariris, que foram praticamente dizimados, e posteriormente as concessões de sesmarias.

Ao longo do tempo, essa estrutura foi sendo alterada em razão de atividades econômicas, dos sistemas de heranças, dos conflitos de terras, ora se fragmentando, ora se reconcentrando, tendo como consequência atualmente profundos contrastes e desigualdades sociais.

Atualmente, esta região vem se tornando o alvo da expansão do agronegócio, que mira a chapada do Araripe como um "território fértil" para o desenvolvimento desse modelo agrícola. Uma das produções que crescem é a fruticultura irrigada, com o destaque para a produção de bananas, dentro dos moldes da monocultura (utilização intensa de agrotóxicos, precárias condições de trabalho, uso excessivo de água, produção voltada para exportação). Além da pecuária extensiva que faz uso da biotecnologia. Reconstruindo assim uma nova divisão social e territorial do trabalho. Esse modelo de produção vem recebendo fortemente incentivo do Estado. Inseridos nesse contexto, existem a resistência de diversos camponeses que vêm desenvolvendo e apontando alternativas de lidar com a terra e gerir o território.

Este estudo vem se construindo como um mosaico unindo as trajetórias e as experiências dessas mulheres, que participam ativamente de movimentos sociais se organizando e confrontando as desigualdades. Além de terem em suas histórias de vida a luta pelo direito à terra, as iniciativas para criação de agroecossistemas/feiras agroecológicas, a participação em sindicatos e os vínculos com a cultura/educação popular.

Dialogando com o que coloca Bartra (2011), um novo modelo de reforma agrária tem em sua premissa um viés de democracia social e cidadã, uma reforma agrária não patriarcal, que tenha um rosto feminino. A soberania alimentar, em seus princípios, busca visibilizar o protagonismo das mulheres nas experiências de transição agroecológicas. Contudo, não se 
resume a empoderar as mulheres em seus espaços sociais, mas transformar as estruturas da sociedade, baseada na exploração, no patriarcado e também no racismo. Suas pautas também apontam para a socialização das tarefas domésticas, repensar a concepção de cuidado e dos bens comuns. Além disso, lutar por paridade nos espaços de lideranças e direções dos movimentos sociais, sindicatos, associações e na posse da terra.

Uma questão central sobre experiências agroecológicas e soberania alimentar, no viés das mulheres, é o acesso à terra. Korol (2016) traz reflexões importantes que para o desenvolvimento da soberania alimentar é necessário garantir a terra às camponesas. E assim fortalecer a reprodução do campesinato, sua alimentação e a produção de alimentos saudáveis para a sociedade. Por fim pontuamos algumas reflexões que a autora traz: Que significa na vida cotidiana das mulheres terem acesso à terra? O que significa para sociedade as mulheres terem acesso ou não à terra?

La primera reivindicación de las mujeres dentro del MST fue que las mujeres sean reconocidas como agricultoras, ya que en los documentos lo que figuraba como profesión era la de "ama de casa". La segunda de ellas es conseguir que todas tengan la documentación exigida en regla, como ciudadanas y como agricultoras, ya que era habitual que no la tuviesen, lo que repercutía en su reconocimiento para poder acceder a la tierra, a ayudas, a créditos y a los derechos que les corresponden como trabajadoras. (LÓPEZ, 2011, apud KOROL, 2016, p. 101)

Hoje, diante de um novo processo de acumulação primitiva, as mulheres são a principal força social que se propõe a interferir no processo da comercialização da natureza. As mulheres através das suas lutas e resistência contribuem na valorização do trabalho de seus filhos e da sua comunidade, desafiando as hierarquias sexuais sobre as quais foi desenvolvido o capitalismo. (FREDERIC, 2019).

Nesse âmbito a globalização dos cuidados - pautado pelas camponesas se opõe à apropriação da riqueza mundial por parte das corporações multinacionais. Valoriza-se a função social da terra, a agricultura como chave para reprodução social e ecológica em grande escala. Assim compreenderemos tais contradições através de suas narrativas de vida e os seus pontos de vista sobre práticas agroecológicas, ser mulher no campo, alimentação, fome, território e soberania alimentar. Neste artigo iremos apresentar a história de vida de duas das oito camponesas entrevistadas, são elas: Dona Ana e Dona Josefa.

Dona Ana nasceu em 1953, no sítio Coités, em Barbalha - Ceará. Em grande parte de sua vida, juntamente com sua família, viveu na condição de moradora "nas terras do patrão". $\mathrm{Na}$ sua trajetória de vida esteve, majoritariamente, ligada à agricultura e trabalhou no corte de cana-de-açúcar. Já foi também lavadeira e sempre que necessário "fazia uns bicos" para 
complementar a renda. Dona Ana foi casada, atualmente é divorciada e teve sete filhos. A agricultora protagonizou diversas lutas e articulações camponesas no Cariri.

Em 1991, ela e diversas famílias deram início à luta pela terra - que hoje é o assentamento 10 de abril. "foram dias de tensos e de enfrentamento." (Dona Ana, informação verbal). Os camponeses ocuparam as terras que outrora foi o Caldeirão do Beato Zé Lourenço. Depois eles foram expulsos e decidiram ocupar o Parque de Exposição Pedro Felício. Após vários dias de resistência com a ocupação conseguiram a posse da terra. Nesse período, além de enfrentar a violência dos latifundiários e do Estado, Dona Ana teve também que enfrentar o marido. Pois ele não aprovava uma mulher estar em um acampamento de "sem terras" juntamente com outros homens.

Ao longo dos anos em parceria com o Sindicato dos Trabalhadores e Trabalhadoras Rurais (STTR) do Crato e da ACB, os camponeses começaram a produzir hortaliças orgânicas e a comercializar os seus produtos. Mais uma vez, Dona Ana foi uma figura muito importante na implementação da feira agroecológica no Crato. Além disso, também contribuiu na organização das mulheres no assentamento 10 de abril, no desígnio para que as mulheres também estejam à frente na direção e nas decisões coletivas do assentamento.

Em 2011, Dona Ana foi entrevistada pelo o jornal o Povo, com o título "A vida entre a flor e a foice". Em 2014, recebeu o prêmio do SESC, o troféu "Mulher de fibra". E por vários anos em seguida participou da Marcha das Margaridas, representando as camponesas do Cariri cearense. Dona Ana e os demais moradores do assentamento vivem um novo processo de territorialização, visto que as obras do Cinturão das Águas (CAC) atravessou uma parte do assentamento 10 de abril, desde 2014. Uma problemática que ainda vem se desenrolando.

Logo, nessa conjuntura destacamos como a questão agrária interfere profundamente no uso e ocupação dos territórios que compõem o cariri cearense. Pois apesar da mobilização social impulsionada pelo movimento agroecológico, articulado em redes pela América Latina, é necessário o acesso à terra como um dos elementos essenciais para a territorialização da Agroecologia. 
Figura 01 - Dona Ana na Feira Agroecológica do Crato - CE.

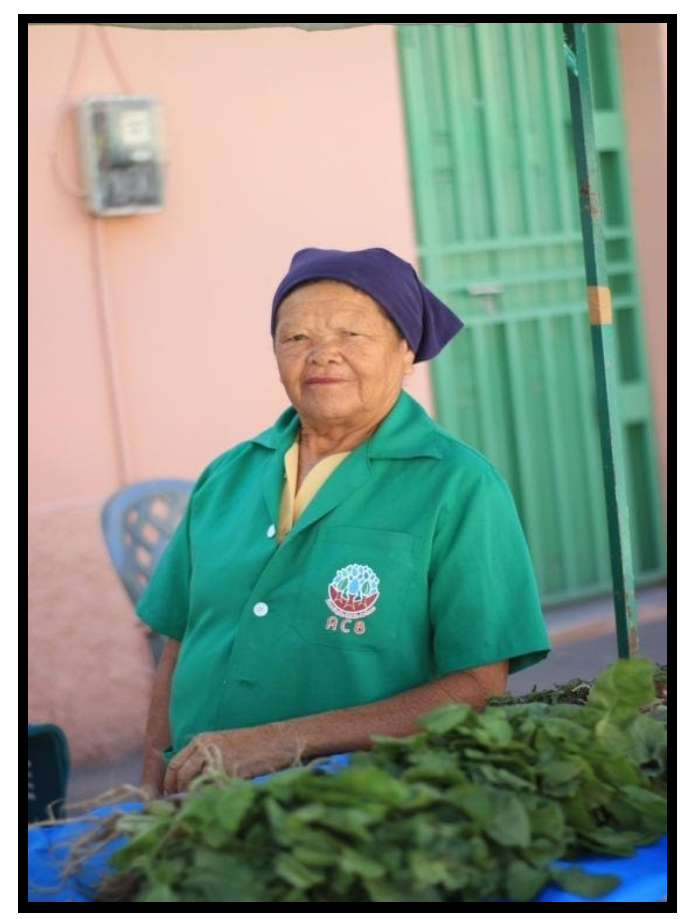

Fonte: Arquivo pessoal. (2019).

Dona Ana vende os seus alimentos na Feira Agroecológica que acontece toda sexta feira, na Rua Cariri, localizada no Centro da cidade do Crato. Uma figura conhecida pelos consumidores. Para a agricultora, a feira é uma importante fonte de sustento. É também um espaço de socialização, de troca de saberes e para conhecer a origem dos alimentos. Então a partir do reconhecimento da sabedoria popular tradicional enquanto agente transformador social, pontuamos seu potencial para atingirmos a soberania alimentar e a conservação da diversidade ecológica e sociocultural.

Ademais pontuamos que os circuitos curtos de produção, como o estabelecimento das feiras agroecológicas, acionam os mercados locais, agregam rendimentos ao campesinato, além de movimentarem os PIBs municipal e estadual. Neste contexto, é importante destacarmos como as articulações e associações de famílias camponesas estão atreladas ao fortalecimento do modo de vida camponês, à territorialização da Agroecologia e aos fluxos da economia local. Por fim, vale destacarmos que nas feiras agroecológicas são comercializados tanto alimentos in natura quanto manufaturados (pães, pastéis, pizzas artesanais, geléias caseiras, polpas de fruta, entre outros). 
Figura 02. Dona Josefa na área de beneficiamento dos alimentos, Crato - CE.

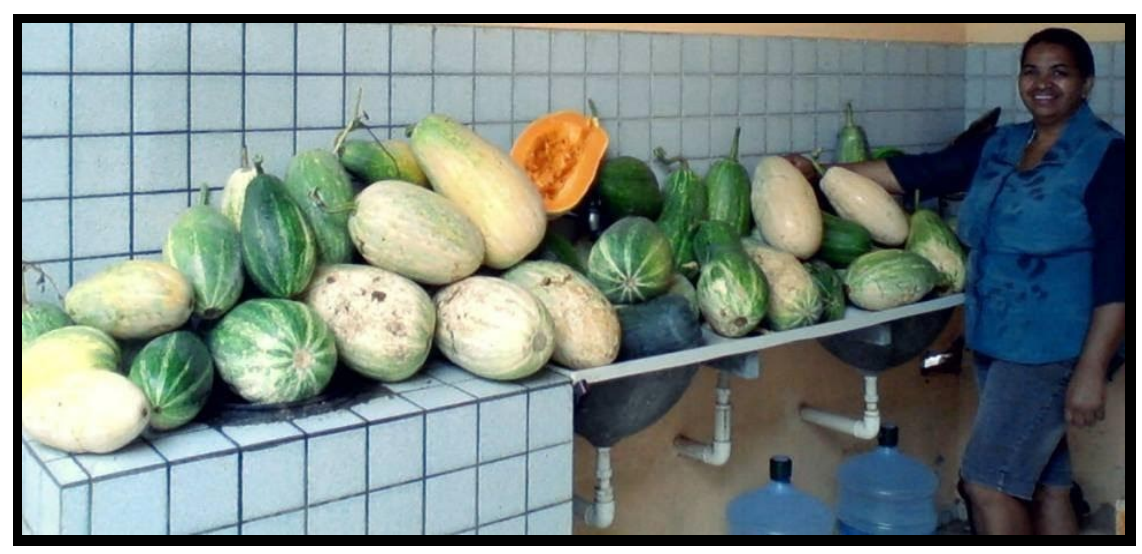

Fonte: Arquivo pessoal (2018).

Josefa Tavares, também conhecida como Zefinha, tem 49 anos, mora na comunidade sítio São Paulo, no município de Caririaçu, casada, mãe de duas filhas e avó. Foi professora na escola da comunidade, possui graduação em Letras e especialização em Psicopedagogia. É uma das co-fundadoras da associação de agricultores da comunidade, nesta associação o intuito é desenvolver a comercialização dos produtos e desenvolver maneiras de realizar o manejo agroecológico. A Associação foi fundada em 12 de maio de 2015 tem nome "Frutos da Terra".

A camponesa agroecológica Josefa também decidiu desenvolver uma atividade de sustentabilidade. Reservando uma parte da sua terra, que se encontrava degradada, para a recuperação com práticas/técnicas agroecológicas. Pois assim além da ação de conscientizar as pessoas ela também poderia mostrar na prática o resultado desse trabalho. Por conseguinte, iniciou um estudo junto com os demais membros da associação sobre o assunto e logo começou a desenvolver essas práticas em sua unidade produtiva, baseando-se também nos preceitos ecológicos do Padre Cícero.

A camponesa relata que se encontrava em um momento muito difícil de sua vida, passando por problemas de saúde, entre eles depressão. Esse trabalho foi a peça fundamental para a melhora de saúde da senhora Josefa. Uma atividade que além do contato com a terra também se dá o contato com as pessoas, com novas experiências, despertando o interesse por mais conhecimento. Ela começou mudando a capinagem do solo, deixando as plantas rasteiras. Para a melhoria do solo, a agricultora também faz uso da adubação verde, a qual usa os restos das podas e o capim gigante. Já para melhoramento na produção faz uso dos fertilizantes naturais, produzidos por ela mesma. 
Dona Josefa faz o plantio de árvores frutíferas como: caju, manga, acerola, cajá, goiaba, jatobá, cajarana, graviola, pinha, araçá, melancia, coco, limão, jaca, banana, pitomba, macaúba, maracujá; também de ervas: capim santo, hortelã, alecrim, cidreira, arruda e de leguminosas: milho, feijão, andú e macaxeira.

Em uma mesma área são cultivadas plantas de porte baixo, médio e alto, deixando ainda sobre o solo as plantas rasteiras. Ela também faz uso de cascas de árvores para a produção de remédios caseiros, como a casca de aroeira. Com suas práticas agroecológicas, esta agricultora vem contribuindo para transformar o território local e possibilidades para uma melhor convivência com o ambiente.

Esses aspectos ressaltam o quanto a camponesa está se reinventando no tempo e no espaço enquanto estratégia para manutenção e fortalecimento do seu modo de vida. Tal recriação representa melhoras sociais, econômicas e laborais na vida do campesinato agroecológico, que vive no cariri cearense, além de promover a conquista de soberania alimentar.

Nesse contexto, ressaltamos a relação intrínseca entre Território CamponêsAgroecologia-Soberania Alimentar, a partir dessa tríade é aspirada a construção de uma sociedade mais justa socialmente e ecologicamente, baseada no diálogo entre os povos, na multiplicidade das cosmovisões, na autonomia, na diversidade ecológica/sócio-cultural e no direito ao território.

\section{CONSIDERAÇÕES FINAIS}

O alimento é uma síntese da organização social vinculada a um determinado tempo espaço, resultante da força de trabalho e da relação sociedade - natureza. Em um grão de milho, tomate cereja ou trigo vai estar contido as relações socioculturais e determinadas configurações socioespaciais onde foram produzidos. Assim, o alimento é um fragmento do seu território de origem.

Atualmente, estamos diante de pelo menos duas formas de modo de produção de alimentos: o Agronegócio e a Agricultura Camponesa. Compreendo que é extremamente pertinente fazermos a diferenciação destes dois tipos de agricultura, os seus projetos de desenvolvimento, os seus interesses de classes e suas capacidades de incluir, ou não, as dimensões ecológicas em suas formas de produção. 
Logo ressaltamos a discussão sobre a agricultura camponesa, que é o foco deste estudo e vem construindo exemplos de produção mais diversificada, orgânica/agroecológica, além de auxiliar no fortalecimento dos saberes tradicionais. Nesse contexto discutimos o papel das mulheres para a consolidação da soberania alimentar em níveis locais e em redes, que dialogam com outras práticas em diversas escalas.

Para isso, nos enveredamos nas histórias de vida das mulheres camponesas, que praticam agroecologia na região do cariri cearense. A partir desse contexto compreendemos como as histórias de vida dessas mulheres estão vinculadas à totalidade sociocultural regional e contribuem para (re)construir as territorialidades camponesas. Portanto na região do Cariri as experiências, que estão sendo realizadas pelas práticas camponesas vêm se mostrando uma alternativa para a produção de alimentos com qualidade, segurança e mais acessibilidade à população.

Por fim ressaltamos o papel do movimento agroecológico, das articulações em rede e das ONGs enquanto elementos fundamentais para a consolidação dos territórios camponeses agroecológicos na América Latina, assim como na dispersão dos ideais que envolvem a agroecologia, são eles: soberania alimentar, feminismo popular camponês e combate aos agrotóxicos.

\section{AGRADECIMENTOS}

Agradecemos à Coordenação de Aperfeiçoamento de Pessoal de Nível Superior (CAPES) por ter financiado esta pesquisa. Este financiamento é de suma importância no processo de consolidação da construção do conhecimento geográfico no Brasil. Assim auxiliando pesquisadoras e pesquisadores a desenvolverem suas pesquisas científicas nas Universidades Públicas Brasileiras.

\section{REFERÊNCIAS}

ARRUZA, Cinzia.; BHATTACHARYA,Titchi.; FRASER, Nancyr. Feminismo para os 99\%: Um Manifesto. São Paulo: Boitempo, 2019.

BARBOSA, Lia P. ROSSET, Peter M. Territorialização da Agroecologia na Via Campesina. In: Revista ECOECO-Agroecologia, 2019. p. 46

BARTRA, A. Os camponeses em questão. In: Os novos camponeses. São Paulo: Cultura Acadêmica; Cátedra Unesco de Educação do Campo e Desenvolvimento Rural, 2011. Pp. 65114. 
CARNEIRO, Henrique. Comida e Sociedade: uma história da alimentação. Rio de Janeiro: ELSEVIER, 2003.

CASTRO, Josué. Geopolítica da Fome. São Paulo: editora Brasiliense, 1965.

CASTRO, Josué. A geografia da Fome. Editora Civilização Brasileira: São Paulo, 2006.

COSTA, M. B. B. Agroecologia no Brasil: história, princípios e práticas. São Paulo: Expressão popular, 2017.

DUTRA; W.; DUTRA, C, P. A reprodução do capital no campo e o território da resistência do campesinato: o movimento dos pequenos agricultores (MPA) na Bahia. In: Campo-Território, Revista de Geografia Agrária, v.3, n. 5, p. 195213, fev. 2008.

FERNANDES, Bernardo Mançano. Territórios y soberanía alimentaria. In: Revista Alasru. Revista latinoamericana de estudo rurales. 2017, vol 2, no 03 .

FEDERICI, Silvia. O ponto Zero: trabalho doméstico, reprodução e luta feminista. Tradução: Coletivo Sycorax. Editora Elefante: São Paulo, 2019

GALEANO, Eduardo. As veias abertas da América Latina. Editora L\&PM: São Paulo, 2010.

HAESBAERT, R. O mito da desterritorialização: do "fim dos territórios" à multiterritorialidade. Rio de Janeiro: Bertrand Brasil, 2004.

KOROL, Claudia. Somos tierra, semillas y rebeldía: mujeres, tierra y territorio en América Latina. GRAIN - Fundación Intomar - OXFAM, 2016.

JALIL. Laeticia, M. Mulheres e Soberania Alimentar: A luta para transformar o meio rural. Programa de Pós - Graduação de Ciências Sociais em Desenvolvimento, Agricultura e Sociedade. Dissertação de Mestrado - Universidade Federal Rural do Rio de Janeiro, 2009.

MARQUES. Marta. I. M. Agricultura e campesinato no mundo e no Brasil. In: PAULINO, Eliane. T. e FABRINI, J.F. (orgs.). Campesinato e territórios em disputa. Expressão Popular: UNESP, Programa de Pós Graduação em Geografia. 2008.

MACHIN SOSA, Braulio et al. A revolução agroecológica: o método camponês a camponês na ANAP em Cuba. São Paulo: Expressão Popular, 2012.

MALUF, R. J. Segurança alimentar e nutricional. Petrópolis, RJ: Vozes, 2007.

MARX, Karl. Manuscritos econômicos -filosóficos. São Paulo: Boitempo, 2010.

MCMICHAEL, P. Regimes alimentares e questões agrárias. São Paulo: Editora UNESP, 2016.

MENEZES, Edith Oliveira. O Cariri Cearense. In: SILVA, J. Borzacchiello da. et al. Ceará: um novo olhar geográfico. Fortaleza: Ed. Demócrito Rocha, 2007.

PAULINO, Eliane T. Por uma geografia dos Camponeses. São Paulo: Editora UNESP, 2012. PORTO-GONÇALVES, C. W. A globalização da natureza e natureza da globalização. Rio de Janeiro: Civilização Brasileira, 2006.

RIGOTTO, Raquel M; AGUIAR, A. C. P. Modelo produtivo do agronegócio, agrotóxicos e saúde humana. In: Júnior, M. A. M.; GARCIA, Maria Franco (Orgs) A questão agrária no século XXI: escalas, dinâmicas e conflitos territoriais. São Paulo.

ROSSET, Peter M. A história das ideias de um movimento camponês transnacional. In: Revista Tensões Mundiais. V14. nº . 27. Editora: EDUECE, Fortaleza, 2018. 
ROSSET, P. La reforma agrária, la tierra y el território: elevolución del pensamento de La Vía Campesina. In: Mundo Agrário, vol 17. № 35, 2016.

SAMPAIO, José L. F. A fome e as duas faces do estado do Ceará. Tese de Doutorado em Geografia. Universidade de São Paulo, 1999.

SCHIMITH, C. J. Transição Agroecológica e desenvolvimento rural: um olhar a partir da experiência brasileira. In: SAUER, S.; B ALESTRO, M. V. Agroecologia e os desafios da transição agroecológica. São Paulo: Expressão Popular, 2009. p. 177203.

SILIPRANDI, Emma. Mulheres e Agroecologia: transformando o campo, as florestas e as pessoas. Rio de Janeiro: Editora UFRJ, 2015.

SHANIN, T. La classe incomoda - Alianza Editorial - Madrid, 1983.

SILVA, Judson Jorge da. Caldeirão e Assentamento 10 de abril: passado e presente na luta por terra no Cariri cearense. Dissertação de Mestrado. Universidade Federal do Ceará, Programa de Pós Graduação em Geografia, Fortaleza, 2010.

VIA CAMPESINA. NGO Forum Declaration in the World Food Summitof, FAO (Rome+5). Roma, junho de 2004. 